\title{
6 The afterlife of the Bronze Age
}

Many aspects of the Bronze Age had a life, as the previous chapters have discussed. People, objects, places and societies all came into being, lived their life, and then passed away. This is what a study of the ancient past consists of - examination of the surviving data, speculating on its meaning, and attempting to understand and describe the phenomena involved.

But the lives I have outlined remain shadowy. We cannot experience Bronze Age life directly, certainly not in pre-literate Europe. We may suppose that Bronze Age people experienced emotions and states of mind just as we do; they interacted with their families and their neighbours, some of them also with people from far outside their local environment. They fought each other, and they exercised the arts of peace. The things people made were an integral part of their interaction with the world around them; they brought them into being and were in turn influenced by them. The places that people inhabited were changed by them, and in turn changed them; the turning of space into place is a social act and reflects social dynamics. And the societies in which people lived were dynamic things, changing and shifting as the interactions between people changed and shifted; the people who lived in those societies were in turn influenced by them.

These lives went on in parallel with the developments in technology and economy that characterise the 1700 years with which I have been concerned. The achievements of the Bronze Age are most easily seen in the craftsmanship of the products of the period, some of which are spectacular. In bronzework, it may be objected that China led the way; nothing in Europe compares with the extraordinary and intricate vessels and figures produced during the Shang Dynasty, coeval with much of the European Bronze Age. Nevertheless, the Trundholm sun chariot, the lurs of Scandinavia or the horns and crotals of Ireland, show a mastery of the medium that reflects a very high degree of skill. The Bronze Age goldwork of Ireland or Scandinavia, or the gold conical hats of central Europe, are on a par with anything produced in gold in China at the same period. The Nebra disc, while not on the same technical level as these objects, is remarkable in a quite different way, indicating as it does an interest in the heavenly bodies that appears to be both developed and sophisticated. In pre-industrial societies, people were obviously much more aware of the bodies in the night sky than we are today; astronomical knowledge was of course highly developed in Egypt and Mesopotamia, and the Nebra disc suggests that there were skilled observers of the night sky in Europe as well. They were also highly skilled in the extraction of minerals from the ground; not just copper and tin, but gold, salt and stone.

Ә OpenAccess. (C) 2021 Harding, published by De Gruyter. (cc) BY-NC-ND This work is licensed under the Creative Commons Attribution-NonCommercial-NoDerivatives 4.0 License. 
But it was not merely physical objects that reflect the knowledge and skills of the Bronze Age. Inferences may be drawn from the sites they created and the evidence of long-distance travel and trade that are apparent in the archaeological record. While Europe was not as advanced as the developed societies of the East Mediterranean in this respect - no palaces, writing, or monumental tombs to compare with the tholos tombs of Greece or the elaborate tombs of Egypt, for instance - nonetheless the elaborate constructions seen on the Swiss lakes or in Iberia or Sicily show that architectural skills were highly developed.

The evidence for travel and trade has been much discussed in recent years, and some of it is described in the preceding pages. In some ways this is the most exciting development in Bronze Age archaeology, and has been responsible for some of the most enterprising accounts of the period, most notably those by Kristian Kristiansen and his collaborators (e.g. Kristiansen and Larsson 2005). I have tended to be sceptical about accepting apparently Mediterranean objects in continental and northern Europe as genuine importations in antiquity, but with the demonstration that travel was a normal part of Bronze Age life it is hard to sustain a position that denies the possibility of long-distance trade - though I maintain that it is right to treat claims of contact objectively, with a careful consideration of context and form.

In economic terms, it is clear that the domestic economy (as represented by foodstuffs and local industries) was supplemented by the movement of goods, or what we may loosely call trade. To some observers this represents an aspect of the "political economy", in which traded goods serve a role as a means for elites to exercise control over resources. Clearly the "economy" of Bronze Age societies was a rather complex matter, even if it cannot be regarded as comparable to a modern economy, or even that of the Roman world. One might argue that there were two parallel economies: one for those who occupied agricultural hamlets (the majority), and another for those who had access to prestige goods. The two must have interacted on some level, but there are many and obvious imponderables in such an analysis.

Individual roles must have been varied, from the more obvious such as craftspeople, those who made the material goods that survive to us, to those whose role was in the psychological or emotional sphere, such as priests and magicians. Weaponry indicates a role for warriors, who may represent many of those of elite status.

All these aspects go to make up the Bronze Age as it survives to us, its achievements and its legacy. But how did that legacy work out in the succeeding centuries? 


\section{The Bronze Age as ancestor to the Iron Age}

Although there are many ways in which the European Iron Age differs from the Bronze Age, it is the regular use of iron that is usually taken as critical in marking the separation; in Greece this happened after $1100 \mathrm{BC}$, in most of continental Europe not until around 800. This of course ignores the fact that iron had been used occasionally for centuries prior to this. Whether the bronze-iron transition in aspects other than metal can be regarded as a break or a change is far from obvious. In purely artefactual and cultural terms the Hallstatt $\mathrm{C}$ period, and its congeners in other parts of Europe, differs in many ways from the preceding Hallstatt B, just as B differs from A, or earlier phases of the Bronze Age from one another. Just to take the eponymous cemetery at Hallstatt: there are graves of the previous phases A and B (not given prominence in discussions of the site), though the most famous belong to phases $\mathrm{C}$ and $\mathrm{D}$; no great break is visible. The only aspect where a clear break is visible is, ironically, in the salt mining: the extensive Bronze Age exploitation came to an apparently abrupt end in the mid $13^{\text {th }}$ century BC. When it resumed, around 300 years later, the technique of extraction was different. This gap is frustrating, since it is the rich graves of Ha $C$ that are usually regarded as a direct consequence of the access to and trade in salt in the Early Iron Age at Hallstatt. This gap appears to be present at Romanian sites as well, though over a different period of time.

The best known aspect of the Hallstatt $\mathrm{C}$ period is the burial evidence, particularly in those areas where richly provided graves occur. Settlement evidence is generally rather poor. While originally the start of the Iron Age was thought to represent the beginning of "Celtic" culture, nowadays scholars are wary of assigning such labels to material culture, and indeed about the idea of a Celtic ethnos identifiable in the archaeological record at all. There is certainly no reason to imagine that the start of $\mathrm{Ha} \mathrm{C}$, in other words the beginning of the Iron Age in central Europe, saw any change in the populations involved - nor does the genetic evidence suggest any such thing. In other words, there is nothing to suggest that the start of the Iron Age, at least in central and western Europe, was more than a series of developments in technology, economy and society, developing on the basis of the preceding Bronze Age phases.

Already in the Urnfield period (periods Bronze D to Hallstatt B), fortified sites became widespread; although in some parts of Europe hillforts are attributed mainly to the Iron Age, there are enough Bronze Age examples to show us that the practice of fortifying naturally defensible sites (or even those in lowland areas) was a common practice. In material culture too, there are plenty of examples of motifs and forms continuing through from the Urnfield to the Hall- 
statt period, for instance the preference for birds and bird elements in decoration on bronzes.

By the middle of the first millennium BC, only a couple of hundred years after the end of the Bronze Age (perhaps six or seven generations), classical Greek civilisation was fully developed; Roman civilisation was highly advanced and would soon emulate Greek. Is there any connection between the Bronze Age cultures of a few hundred years earlier, and the classical civilisations of Greece and Rome? Obviously not a direct one. In the case of Greece, the fact that Linear $B$ is an early form of the Greek language is highly relevant: speakers of the same language were present in the peninsula at least from the middle of the second millennium BC through to the time of the first written form of the language in the first millennium. Debate has continued about the extent to which "Mycenaean culture" (sensu material culture) was extinguished during and after the $12^{\text {th }}$ century BC; there were elements that disappeared and others that continued. There is no genetic evidence for a major change that would represent the "Dorian invasion”, often quoted to explain the demise of Mycenaean culture. In other words, in purely Greek terms, there is no reason to suppose that the inhabitants of Greece in the Bronze Age were anything other than the ancestors of the classical Greeks.

The situation in Italy is more complicated, given the presence of a large and influential group of people - the Etruscans - who spoke a language that is only distantly related (if at all) to Indo-European. But archaeologically speaking, early Etruscan culture developed on the basis of the local version of the Urnfield culture, Villanovan and its predecessor proto-Villanovan. While the precise nature of the relationship between Villanovan and Etruscan is much debated, it is generally accepted that one was ancestral to the other - at least in material culture terms and arguably in terms of populations. In other parts of the peninsula, comparable developments occurred as local variants of proto-Villanovan gave way to successor cultures. The eventual emergence of Latin as the standard language of the whole peninsula, and Rome as the dominant force, took several centuries to accomplish and does not reflect the situation in the late second and early first millennia.

It is inadvisable to suppose that the legal, economic and religious framework that characterised classical Greece and Rome was also present in the societies of those countries several centuries earlier. At the same time, there is plentiful evidence of continuity - at least in material culture terms - from one century to another across the course of the first millennium BC. Greek historians described a deep, mythical or semi-mythical, past that was directly ancestral to their own civilisation, most obviously represented in the rich stories of gods and heroes, of the Trojan War and its aftermath, and similar legends. Religion was a crucial el- 
ement in this. For Greece, the Linear B texts list a series of deities who are regarded as ancestral to those known from Homer and Classical Greece. Sanctuaries such as Delphi, Dodona, or Delos have a Bronze Age presence, and developed strongly during the Early Iron Age. Some of these places evidently remained sacred from the second into the first millennium.

The pattern of tribal societies that emerges in the Iron Age Balkans (Papazoglu 1978) must similarly reflect a deep past: such groupings are very unlikely to have come together in a matter of a century or two following the start of the Iron Age. These political aspects find many echoes in material culture, with some Balkan cemeteries showing continuity through several centuries in the first millennium.

In Europe outside the Mediterranean, the absence of written accounts prevents any comparable analysis, but it would be strange if similar tales of heroic ancestors and battles were not told. Since we lack such information, it is the evidence of material culture that we must use. Technological innovations of the Bronze Age were not forgotten in the ensuing centuries: skill in the working of bronze and other metals, and the manufacture of glass, are among those that continued unbroken into the Iron Age, along with certain artefact types, of which the sword is perhaps the most obvious.

The civilisations of classical Greece and Rome represent the most important influences on western civilisation as it has developed from Renaissance times on, in spite of the many outside influences that continued to make themselves felt. In this sense one can truly say that the Bronze Age background of Greece and Rome is one of the elements that make modern society what it is. Even with the huge number of migrations that have occurred in the last 2000 years, the genetic legacy of prehistory is still evident in modern populations, most clearly that relating to the steppe ancestry that dominated Copper Age populations and went through into the Bronze and Iron Ages. In these several ways, the Bronze Age has an afterlife that affected not only the societies that came immediately after it, but also the living peoples descended from them - including our own European societies. 